\title{
Corrigendum: The Immediate Effect of Therapeutic Touch and Deep Touch Pressure on Range of Motion, Interoceptive Accuracy and Heart Rate Variability: A Randomized Controlled Trial With Moderation Analysis
}

\author{
Darren J. Edwards ${ }^{1 *}$, Hayley Young ${ }^{2}$, Annabel Curtis ${ }^{1}$ and Ross Johnston ${ }^{1}$ \\ ${ }^{1}$ Department of Interprofessional Health Studies, Swansea University, Swansea, United Kingdom, ${ }^{2}$ Department of \\ Psychology, Swansea University, Swansea, United Kingdom
}

Keywords: touch, OMT, interoception, heart rate variability, range of motion

\section{A Corrigendum on}

The Immediate Effect of Therapeutic Touch and Deep Touch Pressure on Range of Motion,

OPEN ACCESS

Approved by:

Frontiers Editorial Office, Frontiers Media SA, Switzerland

*Correspondence:

Darren J. Edwards

d.j.edwards@swansea.ac.uk

Received: 06 April 2020 Accepted: 23 April 2020 Published: 20 May 2020

Citation: Edwards DJ, Young $H$, Curtis $A$ and Johnston R (2020) Corrigendum: The Immediate Effect of Therapeutic Touch and Deep Touch Pressure on Range of Motion, Interoceptive Accuracy and Heart Rate Variability: A Randomized

Controlled Trial With Moderation Analysis.

Front. Integr. Neurosci. 14:28. doi: 10.3389/fnint.2020.00028 Interoceptive Accuracy and Heart Rate Variability: A Randomized Controlled Trial With Moderation Analysis

by Edwards, D. J., Young, H., Curtis, A., and Johnston, R. (2018). Front. Integr. Neurosci. 12:41. doi: 10.3389/fnint.2018.00041

Annabel Curtis was not included as an author in the published article. The author list has been corrected above and the updated Author Contributions Statement appears below.

\section{AUTHOR CONTRIBUTIONS}

DE, HY, RJ, and AC designed the study. DE wrote the majority of the paper with contributions from $\mathrm{HY}$ and AC. HY and DE conducted the majority of the statistical analysis. AC contributed to the research design and some aspects of the writing of this manuscript including some aspects of the statistical analysis.

The authors apologize for this error and state that this does not change the scientific conclusions of the article in any way. The original article has been updated.

Copyright $\odot 2020$ Edwards, Young, Curtis and Johnston. This is an open-access article distributed under the terms of the Creative Commons Attribution License (CC BY). The use, distribution or reproduction in other forums is permitted, provided the original author(s) and the copyright owner(s) are credited and that the original publication in this journal is cited, in accordance with accepted academic practice. No use, distribution or reproduction is permitted which does not comply with these terms. 